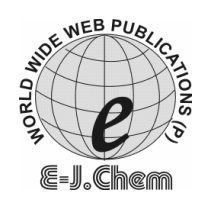

ISSN: 0973-4945; CODEN ECJHAO

\title{
Immersion Calorimetry for the Characterization of PD Catalysts Supported on Activated Carbon
}

\author{
LILIANA GIRALDO and JUAN CARLOS MORENO-PIRAJÁN* \\ Faculty of Sciences, Department of Chemistry, \\ Universidad Nacional de Colombia. \\ *Faculty of Sciences, Department of Chemistry, \\ Research Group of Porous Solids and Applied Calorimetry, \\ Universidad de Los Andes, Colombia. \\ jumoreno@uniandes.edu.co
}

Received 11 November 2008; Accepted 25 January 2009

\begin{abstract}
Activated carbons obtained from coconut peel were oxidized using hydrogen peroxide. Superficial characteristics of these carbons were determined through $\mathrm{N}_{2}$ and $\mathrm{CO}_{2}$ isotherms and functional groups were characterized by TPD. Finally, the microcalorimetry technique was used in order to obtain the immersion enthalpies in diverse liquids and established the relation between them and the results obtained by the other characterization techniques. The results suggested that the immersion calorimetry allow establishing the difference between the supports and the catalysts.
\end{abstract}

Keywords: Catalysts, Activated carbon, Immersion calorimetry, Palladium.

\section{Introduction}

The preparation of supported metallic catalysts is important for a great variety of chemical processes, in which the reactions of interest are facilitated and the energetic content of these processes is modified ${ }^{1-10}$. Mentioning a particular case, inquietudes as producing hydrogen with the lowest $\mathrm{CO}$ generation are still waiting for being solved. Here is where the catalyst selection is worthy of special attention. The metals that shall be used are required to undergo a dispersion process on a porous solid that preferably has a great superficial area to obtain a maximum of active phase. Generally, the highly dispersed catalysts possess a greater activity per gram of metal because they contain small metal crystals, allowing that a good proportion of the metal is available for the reactive molecules ${ }^{11-15}$.

The variables of interest during the catalysts preparation and which affect the properties of the final product are several. Among the most important are: (a) metallic precursor, (b) support, 
(c) deposition technique of the metallic precursor on the support, (d) weight percentage of the metal on the catalyst, (e) catalyst activation procedure (reduction, sulphuration, etc) and (f) support chemical treatment. The palladium active sites are influenced by some factors, such as the particle size, support interaction and salts nature; among others. The present research study of palladium catalysts supported on activated carbon and the influence of the thermal and chemical treatment on the supports characteristics is analyzed.

\section{Experimental}

For the preparation of the supports used in this study, activated carbon from coconut peel was employed by $\mathrm{N}_{2}$ flux carbonization and posterior activation using water steam. From this material, diverse supports were obtained by different treatments. A portion of the carbon was left on its original state to be thermal and chemical treated (CA1-series). Another part of the carbon was purified with sulfuric acid for the reduction of the mineral ashes content and later was taken at $1273 \mathrm{~K}$ for four hours in nitrogen flux $\left(100 \mathrm{~mL}\right.$. $\left.\mathrm{min}^{-1}\right)$ to obtain the CA2 carbons.

The CA1 carbon was oxidized using $6 \mathrm{~N}$ hydrogen peroxide to introduce oxygen superficial groups. The procedure is as follows: $20 \mathrm{~g}$ of carbon were heated at mechanic vacuum at $453 \mathrm{~K}$ to be then cooled down at room temperature. $250 \mathrm{~cm}^{3}$ of the oxidizing agent were added and the mixture was kept into contact during 72 hours with stirring at room temperature. Finally, the carbon was filtrated through a syntherized glass plaque and washed with bidistilled water until peroxide absence. This way, the CA1OxP support was obtained. A part of the same carbon was later treated using a $\mathrm{N}_{2}$ flux $\left(100 \mathrm{~mL} \mathrm{~min}^{-1}\right)$ during four hours at $780 \mathrm{~K}$ to eliminate the superficial groups that appeared to be less stable in order to obtain the CA1OxPT1 support.

The CA2 activated carbon suffered the same process than CA1, producing the CA2OxP and CA2OxPT1 carbons. The ashes content of the carbons CA1 y CA2 was determined by the standard method ${ }^{2}$.

The characterization of the carbons porous structure was carried out through the physical adsorption of $\mathrm{N}_{2}$ at $77 \mathrm{~K}$ and $\mathrm{CO}_{2}$ at $273 \mathrm{~K}$ using an automatic AUTOSORB 3B (QUANTACHROME). The superficial groups have been determined through the temperature desorption programmed technique (TPD) using a micromeritics equipment.

The samples $(0,1 \mathrm{~g}$ aprox.) were set in a quartz microreactor and then treated with $\mathrm{He}$ flux $\left(50 \mathrm{~mL} \cdot \mathrm{min}^{-1}\right)$ for one hour. Afterward, they were heated at a velocity of $10 \mathrm{~K} \mathrm{~min}{ }^{-1}$ until $1273 \mathrm{~K}$. The decomposition products $\left(\mathrm{CO}, \mathrm{CO}_{2}\right.$ and $\left.\mathrm{H}_{2} \mathrm{O}\right)$ were analyzed using a Balzers cuadrupolar mass spectrometer model MSC 200 bound to the reactor.

\section{Catalysts}

Two different salts were selected for the preparation of the palladium catalysts on activated carbon: $\mathrm{Pd}\left(\mathrm{NO}_{3}\right)_{3}$ and $\mathrm{Pd}\left(\mathrm{NH}_{3}\right)_{4} \mathrm{Cl}_{2}$. With the first precursor, the incipient impregnation method was applied, using an aqueous dissolution in the proportion of $0.5 \mathrm{~mL}$ per gram of support. For the $\mathrm{Pd}\left(\mathrm{NH}_{3}\right)_{4} \mathrm{Cl}_{2}$, the method of absorption in aqueous dissolution was employed. The supports erre kept into contact with the dissolution during 12 hours and the supernatant was evaporated using a water bath.

In all cases, the dissolution concentration and volume was the appropriate for obtaining a palladium charge of approximately, $2 \%$ in weight. All catalysts were dried at 373-383 K overnight.

Four groups of catalysts were then obtained: one per each precursor, to which two series of supports correspond. The catalysts were called using the palladium symbol and the name of the support. The catalysts obtained by the palladium trinitrate(III) complex have been 
distinguished by their symbol and oxidation state. So, Pd(III) CA2, shall be a palladium catalyst supported on the CA2 activated carbon and prepared from palladium nitrate and Pd(II) CA2 shall be a similar catalyst but prepared from tetraamminpaladio chloride(II).

The palladium dispersion on the catalysts has been carried out by the hydrogen chemical adsorption at $298 \mathrm{~K}$; the samples previously degasificated at vacuum at room temperature, were reduced in hydrogen atmosphere $\left(50 \mathrm{~mL} \cdot \mathrm{min}^{-1}\right)$ at $623 \mathrm{~K}$ for 12 hours. The catalysts were characterized through the physical adsorption of $\mathrm{N}_{2}$ at $77 \mathrm{~K}$ and of $\mathrm{CO}_{2}$ at $273 \mathrm{~K}$ using an automatic AUTOSORB 3B equipment and the programmed temperature desorption (DTP) with a micromeritics device.

For each catalyst, immersion calorimetries were determined; $0.1 \mathrm{~g}$ samples were desorbed at $383 \mathrm{~K}$ and at a vacuum of $1 \times 10^{-5} \mathrm{mBar}$ for 24 hours. Each sample was then put in a cell that contains the liquid in which the immersion was performed. Each measurement contains an electric calibration. In Figure 1, the general scheme of the microcalorimeter employed is shown ${ }^{16}$.

\section{Immersion enthalpies}

The degasificated sample in the glass ampoule was set inside the immersion microcalorimeter (Figure 1). Once the baseline becomes stable, the breakage of the ampoule inside the studied liquid takes place and an electric calibration was performed posterior to the generation of the thermal effect. The immersion enthalpies in $\mathrm{NaOH}$ and $\mathrm{HCl}$ were carried out using $1 \mathrm{~N}$ solution.

Each determination was repeated five times. The immersion enthalpy in benzene, $\Delta \mathrm{H}_{\mathrm{C} 6 \mathrm{H} 6}$, was done controlling the samples interaction because this enthalpy shows superficial-type parameters.

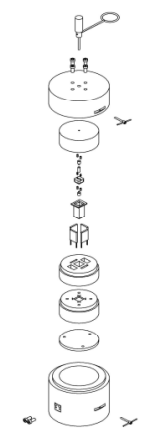

Figure 1. Immersion calorimeter.

\section{Results and Discussion}

The $\mathrm{N}_{2}$ and $\mathrm{CO}_{2}$ adsorption isotherms at $77 \mathrm{~K}$ and $273 \mathrm{~K}$ respectively. The $\mathrm{CO}_{2}$ adsorption isotherms at $273 \mathrm{~K}$ are shown in Figure 2.

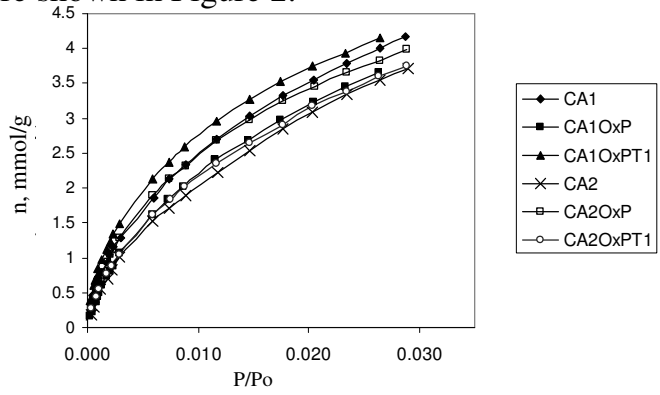

Figure 2. Carbon dioxide desorption isotherms at $273 \mathrm{~K}$. 
Table 1 summarizes the BET superficial areas and the micropores volume for each support obtained from the nitrogen adsorption isotherms and from the zone of relative low pressures of the $\mathrm{N}_{2}$ and $\mathrm{CO}_{2}$ adsorption isotherms, respectively.

Table 1. Superficial areas and micropores volume corresponding to the employed carbonaceous supports.

\begin{tabular}{lccc}
\hline Sample & $\mathrm{N}_{2}$ at 77K & & $\mathrm{CO}_{2}$ at $273 \mathrm{~K}$ \\
\hline & SBET & VO(DR) & VO(DR) \\
CA1 & 820 & 0.37 & 0.30 \\
CA1OxP & 810 & 0.37 & 0.30 \\
CA1OxPT1 & 887 & 0.40 & 0.21 \\
CA2 & 950 & 0.43 & 0.29 \\
CA2OxP & 930 & 0.39 & 0.33 \\
CA2OxPT1 & 980 & 0.39 & 0.30 \\
Pd(III)CA1 & 567 & 0.27 & 0.22 \\
Pd(III)CA1OxP & 518 & 0.27 & 0.21 \\
Pd(III)CA2 & 620 & 0.21 & 0.20 \\
Pd(III)CA2OxP & 600 & 0.20 & 0.15 \\
Pd(II)CA1 & 510 & 0.18 & 0.14 \\
Pd(II)CA1OxP & 476 & 0.17 & 0.16 \\
Pd(II)CA2 & 550 & 0.17 & 0.14 \\
Pd(II)CA2OxP & 510 & 0.16 & 0.16 \\
\hline
\end{tabular}

As shown in Figure 2, the CA1 shows an inferior adsorption in the zone of relative low pressures, suggesting a narrow microporosity. Consequently, it presents the lowest micropores volume, as Table 1 illustrates.

The intermediate zone of the curve shows a quasi-horizontal slope, indicating a scarce mesoporosity. The CA2 support is found to be on the opposite side about both, the superficial area and the micropores volume, whereas an increase due to the purification process and thermal treatment appeared to take place. The posterior zone of the isotherm elbow, presents a more pronounced slope, indicating a greater development of the mesoporosity (pores widening). The augment of the micropores volume can be attributed to the impurities elimination (gasification).

The posterior treatment at $773 \mathrm{~K}$ of the oxidized CA1 carbon slightly increases the superficial area, at the same time that increases to some extent the micropores volume determined by the $\mathrm{N}_{2}$ adsorption at $77 \mathrm{~K}$. It is important to note the fact that the volume of the more narrowed micropores has considerably decreased as a consequence of the thermal treatment of this carbon. Also, the elbow of the isotherm seems to be wider. These facts are evidence of the greater porosity development, which is in accordance to the superficial area increase.

When the fixation of the palladium on the supports arises, the superficial area is modified and according to the ionic radios for both, the $\mathrm{Pd}^{3+}$ and the $\mathrm{Pd}^{2+}(0.0072$ and 0.093 $\mathrm{nm}$ respectively), it may be observed that the area for the supports with $\mathrm{Pd}(\mathrm{III})$ is greater than their superficial area in relation with the catalysts obtained using $\mathrm{Pd}(\mathrm{II})$.

In general, the CA2 oxidation has the effect of diminishing both, the superficial area and the micropores volume without altering the most narrowed mircroporosity. A tendency to match between the isotherms may be seen in the final zone, indicating a similar macropores 
distribution. The posterior thermal treatment of this material generates an isotherm extremely alike with the previous one. This same behavior can be observed with the $\mathrm{CO}_{2}$ isotherms in Figure 2.

\section{Temperature programmed decomposition}

The decomposition graphs at programmed temperature for the series CA1 catalysts are shown in Figure 3.

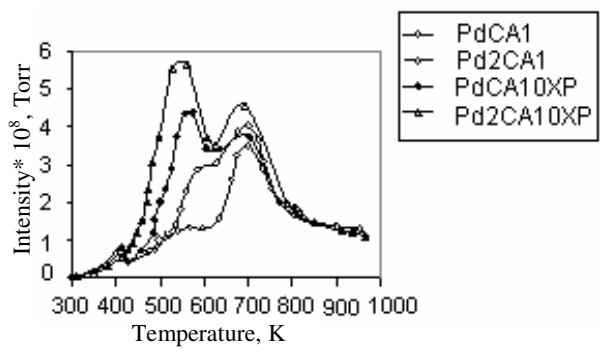

Figure. 3. TPD Profiles for $\mathrm{CO}_{2}$ of the CA1 supports.

The TPD results are summarized in Table 2.

Table 2. TPD of the catalysts on the activated carbons with different oxidation states.

\begin{tabular}{lcccc}
\hline \multicolumn{1}{c}{ Sample } & $\mathrm{CO}, \mathrm{m} \mathrm{mol} \mathrm{g}^{-1}$ & $\mathrm{CO}_{2}, \mathrm{~m} \mathrm{~mol} \mathrm{~g}^{-1}$ & $\mathrm{CO} / \mathrm{CO} 2$ & $\mathrm{O}, \mathrm{m} \mathrm{mol} \mathrm{g}^{-1}$ \\
\hline CA1 & 0.35 & 0.15 & 2.3 & 0.30 \\
CA1OxP & 1.12 & 0.28 & 4.0 & 0.53 \\
CA1OxPT1 & 1.05 & 0.3 & 3.5 & 0.48 \\
CA2 & 0.38 & 0.15 & 2.5 & 0.45 \\
CA2OxP & 1.45 & 0.55 & 2.6 & 0.60 \\
CA2OxPT1 & 1.32 & 0.32 & 4.1 & 0.50 \\
Pd(III)CA1 & 0.3 & 0.09 & 3.3 & 0.27 \\
Pd(III)CA1OxP & 0.93 & 0.22 & 4.2 & 0.36 \\
Pd(III)CA2 & 0.35 & 0.09 & 3.9 & 0.37 \\
Pd(III)CA2OxP & 1.27 & 0.43 & 3.0 & 0.52 \\
Pd(II)CA1 & 0.24 & 0.06 & 4.0 & 0.22 \\
Pd(II)CA1OxP & 0.86 & 0.17 & 5.1 & 0.28 \\
Pd(II)CA2 & 0.2 & 0.06 & 3.3 & 0.31 \\
Pd(II)CA2OxP & 0.77 & 0.36 & 2.1 & 0.39 \\
\hline
\end{tabular}

These results from TPD for the supports and catalysts. It may be seen that using the supports treated with hydrogen peroxide, the superficial groups containing oxygen, augment; as studies have previously reported. The same behavior may be seen for the catalysts obtained with Palladium. The relation $\mathrm{CO} / \mathrm{CO}_{2}$ particularly increases with the thermal treatment and the hydrogen peroxide

\section{Immersion calorimetry}

In Table 3, the results of the immersion heats of each support and the catalyzed in benzene, water, sodium hydroxide and chloride acid are shown. It is important to remark that the immersion enthalpy does not become modified by the oxygen content of the material, which corroborates the observation that soft oxidation processes do not modify the structural properties of the original support, aspect confirmed by Barton ${ }^{17-18}$. There is a change in the 
immersion enthalpies using benzene between the supports and the catalysts; which is coherent because the support structure changes once the palladium is fixed. This shows that the microcalorimetric technique allows establishing these differences.

Table 3. Immersion enthalpies for each catalyst.

\begin{tabular}{lcccccc}
\hline & $\begin{array}{c}-\Delta \mathrm{H}_{\mathrm{C} 6 \mathrm{H} 6}, \\
\mathrm{~J} \mathrm{~g}^{-1}\end{array}$ & $\begin{array}{r}\Delta \mathrm{J} \mathrm{g}_{2} \mathrm{O}, \\
\mathrm{J} \mathrm{g}^{-1}\end{array}$ & $\begin{array}{c}\Delta \mathrm{NaOH}, \\
\mathrm{J} \mathrm{g}^{-1}\end{array}$ & $\begin{array}{c}\Delta \mathrm{HCl}, \\
\mathrm{J} \mathrm{g}^{-1}\end{array}$ & $\begin{array}{c}\Delta \mathrm{Hi}, \\
\mathrm{NaOH}, \text { net }\end{array}$ & $\begin{array}{c}\Delta \mathrm{HCl}, \\
\text { net }\end{array}$ \\
\hline CA1 & 124 & 24.9 & 41.5 & 70.5 & 16.6 & 45.6 \\
CA1OxP & 134 & 54.8 & 83.4 & 94.5 & 28.6 & 39.7 \\
CA1OxPT1 & 128 & 68.7 & 94.6 & 100 & 25.9 & 31.8 \\
CA2 & 130 & 32.7 & 43.5 & 85.7 & 10.8 & 53.0 \\
CA2OxP & 135 & 66.9 & 91.4 & 112 & 24.5 & 45.9 \\
CA2OxPT1 & 139 & 75.2 & 102 & 140 & 27.1 & 65.6 \\
Pd(III)CA1 & 82.5 & 16.5 & 21.6 & 30.5 & 5.10 & 14.0 \\
Pd(III)CA1OxP & 78.5 & 32.6 & 44.7 & 42.6 & 12.1 & 10.0 \\
Pd(III)CA2 & 88.4 & 26.5 & 32.5 & 44.7 & 6.00 & 18.2 \\
Pd(III)CA2OxP & 84.6 & 36.5 & 47.9 & 62.1 & 11.4 & 25.6 \\
Pd(II)CA1 & 72.7 & 11.2 & 18.9 & 28.7 & 7.70 & 17.5 \\
Pd(II)CA1OxP & 65.8 & 21.4 & 30.4 & 37.5 & 9.00 & 16.1 \\
Pd(II)CA2 & 85.8 & 17.4 & 24.4 & 33.7 & 7.00 & 16.3 \\
Pd(II)CA2OxP & 79.5 & 25.3 & 36.7 & 53.6 & 11.4 & 28.3 \\
\hline
\end{tabular}

In Figure 4 the immersion enthalpies are shown. Whether the behavior is carefully compared to the oxygen content $\left(\mathrm{mmol} \mathrm{g}^{-1}\right)$ reported in Table 2, it may be deduced that there is a direct correlation. The immersion enthalpies are greater in the three assayed molecules. The neutralization net enthalpy is the difference between the neutralization enthalpy and the immersion enthalpy in water,

$$
\begin{aligned}
\Delta \mathrm{Hi}(\mathrm{NaOH})_{\text {net }} & =\Delta \mathrm{Hi}(\mathrm{NaOH}) \\
\text { and } & -\Delta \mathrm{Hi}\left(\mathrm{H}_{2} \mathrm{O}\right) \\
\Delta \mathrm{Hi}(\mathrm{HCl})_{\text {net }} & =\Delta \mathrm{Hi}(\mathrm{HCl})-\Delta \mathrm{Hi}\left(\mathrm{H}_{2} \mathrm{O}\right)
\end{aligned}
$$

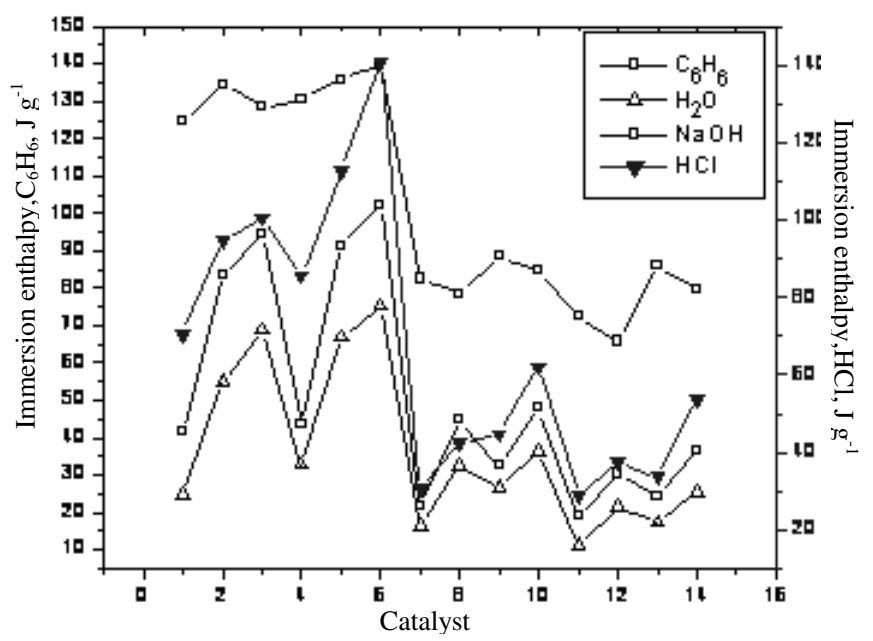

Figure 4. Immersion enthalpies of the supports and catalysts. 
It is shown that both, the net immersion enthalpies in $\mathrm{NaOH}$ that determine acid groups and the net enthalpies in $\mathrm{HCl}$ that establish basic groups, decrease in the catalysts, which is logical because part of the functional groups are used by the Palladium ions when these are fixed on the activated carbons.

This investigation shows that the microcalorimetry as technique may distinguish not only the functional groups, as previous studies by Moreno et.al ${ }^{18}$ had already reported but the differences between the catalysts, and these results are complementary to the obtained through other techniques.

\section{Conclusions}

The present study shows that the microcalorimetric technique is highly sensitive and that it can be used as a complementary method to establish changes in the chemical surface, not only of the supports for the catalysts according to their treatment, but for the same catalysts. The enthalpy values change according to the catalysts treatments.

\section{Acknowledgements}

The authors thank to the frame agreement between the Universidad Nacional de Colombia and the Universidad de los Andes (Colombia) under this investigation could be accomplished. Additionally Prof. Moreno wants to especially thanks to Universidad de los Andes for the assignation of a STAI, which was partially used to do this research.

\section{References}

1. Taylor K C, Catal Rev Sci Eng., 1993, 35(4), 457.

2. Kobylinski T P and Taylor B W, J Catal., 1974, 33(3), 376.

3. Adams K.M and Gandhi H S, Ind Eng Chem Prod Res Dev., 1983, 22, 207.

4. Ghandi H S, Yao H C and Stepien H K, Catalysis Under Transient Conditions (Bell A T and Hegedus L. L, Eds.), ACS Symposium Series, ACS: Washington, DC, 1982, 178, p143.

5. Halasz I, Brenner A, Shelef M and Simon K Y, Appl Catal A., 1992, 82(1), 51.

6. Halasz I, Brenner A and Shelef M, Appl Catal B., 1993, 2(1), 131.

7. Hoost T E, Graham G W, Shelef M, Alexeev O and Gates B C, Catal Lett., 1996, 38(1-2), 57.

8. Miguel H and de Andrade J B, J Braz Chem Soc., 1990, 1, 124.

9. Noronha F B, Schmal M, Primet M and Frety R, Appl Catal., 1991, 78(1), 125.

10. Benson J E, Hwang H S and Boudart M, J Catal., 1973, 30(1), 146.

11. Rakai A, Tessier D and BozonVerduraz F, New J Chem., 1992, 16, 869.

12. Chung K S and Massoth F E, J Catal., 1980, 64(2), 20.

13. Chen G, Chou W T, Yeh C T, Appl Catal., 1983, 8(3), 389.

14. Chang T C, Chen J J, and Yeh C T, J Catal., 1985, 96(1), 51.

15. Yao H C, Appl Surf Sci., 1984, 19, 398.

16. Giraldo L, Huertas J I, Valencia A and Moreno J C, Inst Sci Technol, 2003, 31(4), 385.

17. Barton S S, Evans M J B, Halliop E and MacDonald J A F, A, Carbon, 1997, 35(9), 1361.

18. Carrasco-Marín F, Muedenv, Centeno T A, Stoeckli F and Moreno-Castilla C, $J$ Chem Soc Faraday Trans., 1997, 93, 2211. 


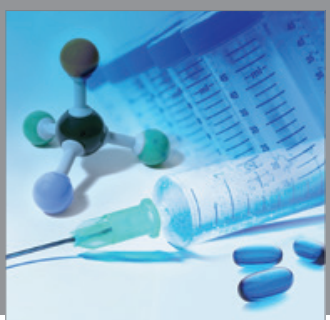

International Journal of

Medicinal Chemistry

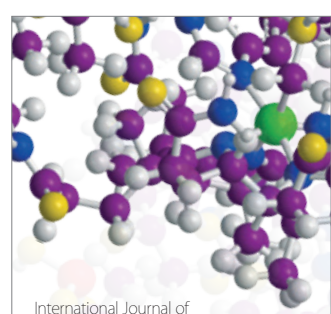

Carbohydrate Chemistry

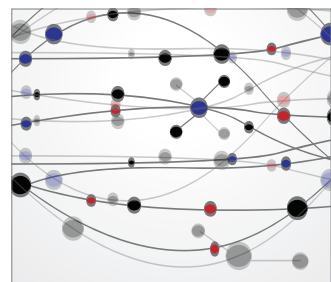

The Scientific World Journal
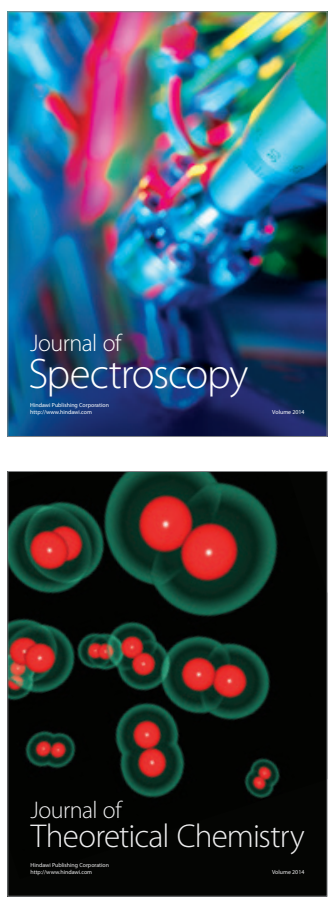
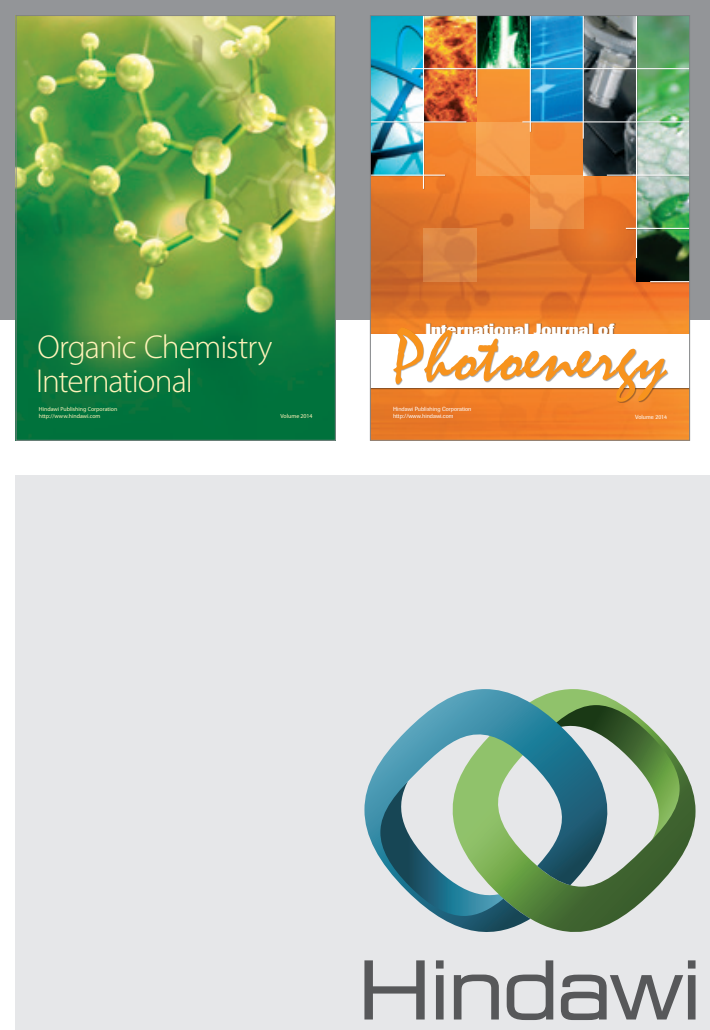

Submit your manuscripts at

http://www.hindawi.com
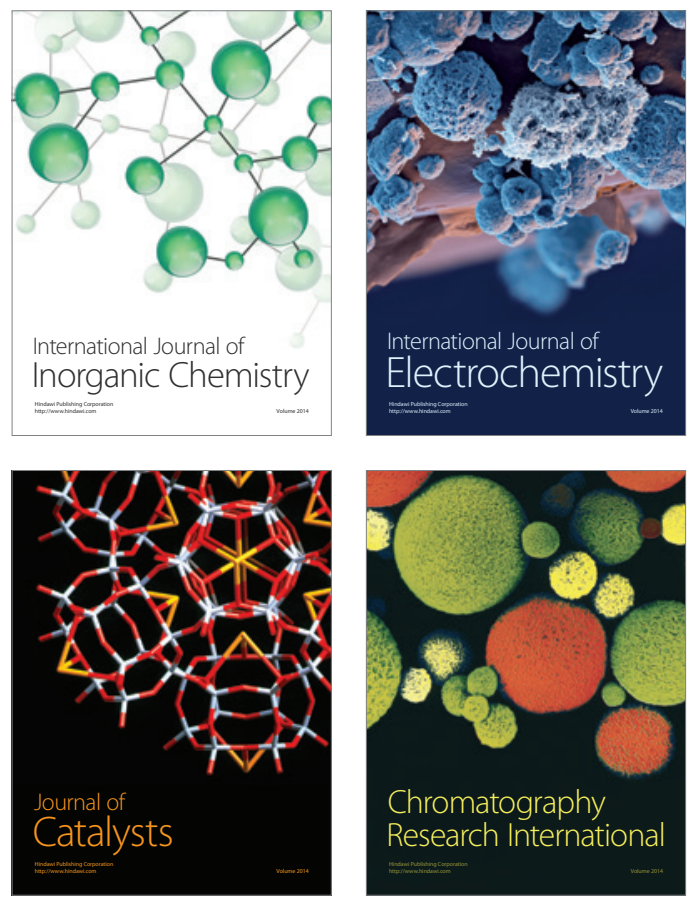
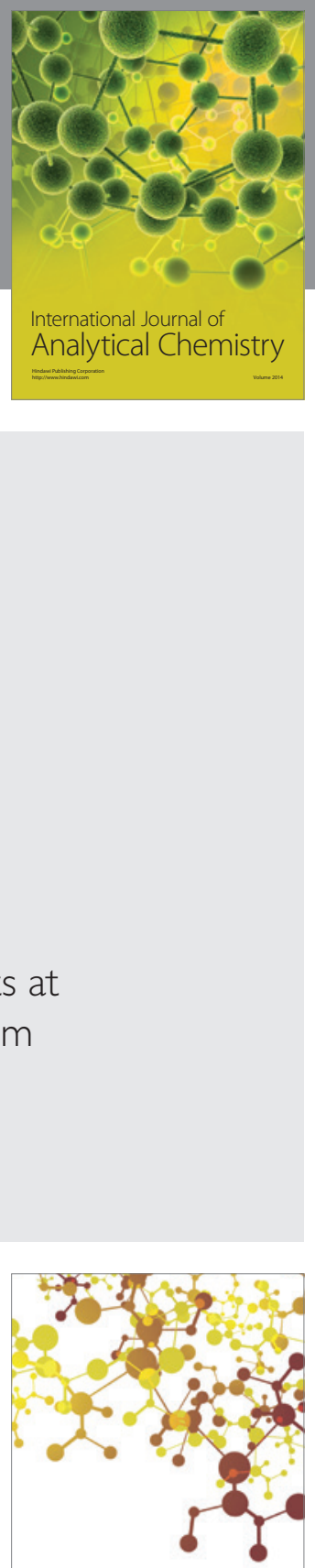

Journal of

Applied Chemistry
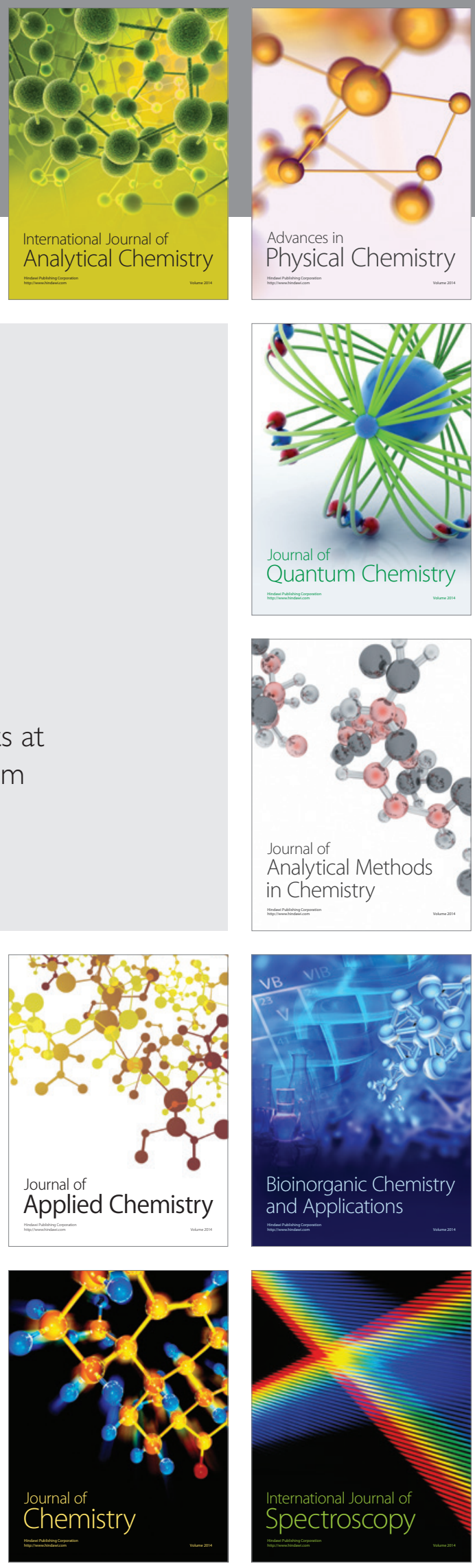